Sato et al.

\title{
"revised highlighted"
}

\section{Timing of CRISPR/Cas9-related mRNA microinjection after activation as an important factor affecting genome editing efficiency in porcine oocytes}

Masahiro Sato a,", Kosuke Maeda ${ }^{\mathrm{b}}$, Miyu Koriyama ${ }^{\mathrm{b}}$, Emi Inada ${ }^{\mathrm{c}}$, Issei Saitoh ${ }^{\mathrm{d}}$, Masato Ohtsuka ${ }^{\mathrm{e}, \mathrm{f}}$,

5 Shingo Nakamura ${ }^{\mathrm{g}}$, Takayuki Sakurai ${ }^{\text {h}}$, Satoshi Watanabe ${ }^{\mathrm{i}}$, Kazuchika Miyoshi ${ }^{\mathrm{b}}$

${ }^{a}$ Section of Gene Expression Regulation, Frontier Science Research Center, Kagoshima University, Kagoshima 890-8544, Japan

${ }^{b}$ Laboratory of Animal Reproduction, Faculty of Agriculture, Kagoshima University, Kagoshima 890-0065, Japan 'Department of Pediatric Dentistry, Graduate School of Medical and Dental Sciences, Kagoshima University,

10 Kagoshima 890-8544, Japan

${ }^{d}$ Division of Pediatric Dentistry, Department of Oral Health Sciences, Course for Oral Life Science, Graduate School of Medical and Dental Sciences, Niigata University, Niigata 951-8514, Japan

${ }^{e}$ Division of Basic Molecular Science and Molecular Medicine, School of Medicine, Tokai University, Kanagawa 259-1193, Japan

$15{ }^{f}$ The Institute of Medical Sciences, Tokai University, Kanagawa 259-1193, Japan

${ }^{\mathrm{g}}$ Division of Biomedical Engineering, National Defense Medical College Research Institute, Saitama 359-8513, Japan

${ }^{h}$ Basic Research Division for Next-Generation Disease Models and Fundamental Technology, Research Center for Next Generation Medicine, Shinshu University, Nagano 390-8621, Japan

$20{ }^{i}$ Animal Genome Research Unit, Division of Animal Science, National Institute of Agrobiological Sciences, Ibaraki 305-8602, Japan

"Author's address (for correspondence): Prof/Dr. Masahiro Sato, Section of Gene Expression Regulation, Frontier Science Research Center, Kagoshima University, 8-35-1 Sakuragaoka, Kagoshima, Kagoshima 890-8544, Japan

25 E-mail: masasato@m.kufm.kagoshima-u.ac.jp

Running head: Improvement of microinjection-based genome editing in swine 
Sato et al.

\begin{abstract}
Recently, successful one-step genome editing by microinjection of CRISPR/Cas9-related mRNA components into the porcine zygote has been described. Given the relatively long gestational period and the high cost of housing swine, the establishment of an effective microinjection-based porcine genome editing method is urgently required.

5 Previously, we have attempted to disrupt a gene encoding $\alpha$-1,3-galactosyltransferase (GGTA1), which synthesizes the $\alpha$-Gal epitope, by microinjecting CRISPR/Cas9-related nucleic acids and enhanced green fluorescent protein $(E G F P)$ mRNA into porcine oocytes immediately after electrical activation. We found that genome editing was indeed induced, although the resulting blastocysts were mosaic and the frequency of modified cells appeared to be low (50\%). To improve genome editing efficiency in porcine oocytes, cytoplasmic injection was performed $6 \mathrm{~h}$

10 after electrical activation, a stage wherein the pronucleus is formed. The developing blastocysts exhibited higher levels of EGFP. Furthermore, the T7 endonuclease 1 assay and subsequent sequencing demonstrated that these embryos exhibited increased genome editing efficiencies (69\%), although a high degree of mosaicism for the induced mutation was still observed. Single blastocyst-based cytochemical staining with fluorescently labeled isolectin BS-I-B $\mathrm{B}_{4}$ also confirmed this mosaicism. Thus, the development of a technique that avoids or reduces such mosaicism would be a key factor for efficient knock out piglet production via microinjection.
\end{abstract}

Keywords: $\alpha$-Gal epitope; $\alpha$-1,3-galactosyltransferase; CRISPR/Cas9; microinjection; mRNA; mosaicism; biallelic KO; indels; isolectin BS-I-B4 
Sato et al.

\section{Introduction}

Recently, a series of nuclease-based genome editing technologies, including zinc-finger nuclease (ZFN), transcription activator-like effector nucleases (TALEN), and clustered regularly interspaced short palindromic repeats (CRISPR)/CRISPR-associated (Cas)9 (CRISPR/Cas9), have been developed. They enable targeted and efficient modification of a variety of eukaryotic species, particularly mammalian [1,2]. In the case of CRISPR/Cas9-based genome editing, it requires a guide RNA (gRNA) which can bind to the specific chromosomal DNA site together with the Cas9 endonuclease [3-6]. Once bound, two independent nuclease domains in Cas9 will each cleave one of the DNA strands 3 bases upstream of the protospacer adjacent motif (PAM), introducing double-strand breaks (DSBs) at the host chromosome target site, which are repaired by non-homologous end-joining (NHEJ). The NHEJ-based repair process generates nucleotide insertion or deletion (indel mutations), or causes a frame-shift, which disables encoded proteins or forms premature stop codons, ultimately leading to the generation of a loss-of-function allele. Due to the difficulties in design and assembly, and the limited availability of target sites [7], CRISPR/Cas9 is becoming the most frequently used tool for producing genetically modified organisms [1,2]. To perform CRISPR/Cas9-mediated genome editing efficiently, the selection of appropriate gRNA is important, since targeting efficiency can vary between loci, and even between target sites within the same locus [8-10].

Direct zygotic injection of CRISPR/Cas9 components is becoming a major tool for the production of biallelic knock out (KO) animals, including mice, rats, rabbits, and monkeys [11-18]. In the case of KO pig production, Hai et al. [19] first demonstrated that cytoplasmic injection of mRNAs as CRISPR/Cas9 components into zygotes isolated from oviducts, and subsequent return of the treated zygotes to the source oviducts, led to the production of biallelic KO piglets. Whitworth et al. [20] also achieved similar results using in vitro-produced zygotes. These findings encouraged us to produce KO piglets through one-step injection of CRISPR/Cas9-related components (mRNA) into zygotes. On this occasion, the most important issue was determining the appropriate gRNA to enable efficient genome editing. Most porcine studies have focused on molecular analysis of resulting fetuses or newborns to confirm the presence of genome editing-induced mutations; determining whether the constructed gRNA is optimal for efficient target gene KO is both time-consuming and labor-intensive. Sakurai et al. [21] proposed a single blastocyst-based assay in mice, which is centered on the T7 endonuclease 1 (T7E1)-based cleavage assay for CRISPR/Cas9-induced indel detection. They used repeated PCR of genomic DNA isolated from a single blastocyst for target region amplification and successfully identified mutant alleles. In mice and swines, it takes 3 and 7 days, respectively, to reach the blastocyst stage after fertilization. Therefore, rapid evaluation is possible if blastocysts are used for molecular analyses. The other advantage to using a single blastocyst as an experimental target is that localization of the protein generated from a target locus can be simply assessed by cytological methods using lectin or antibody probes. In other words, assessing the consequence of mutations at a target locus should be possible by single embryo staining in the presence of such probes.

$\alpha-1,3$-galactosyltransferase ( $\alpha$-GalT) synthesizes the $\alpha$-Gal epitope (Gala1-3Galß1-4GlcNAc-R), which is expressed on the cell surface in almost all mammals, except for humans and Old World monkeys [22,23]. The $\alpha$-Gal epitope is specifically recognizable by staining with the isolectin, BS-I-B 4 (IB4) $[24,25]$. We have previously described the expression of $\alpha$-Gal epitope in porcine embryos using quantitative reverse transcription (RT)-PCR

40 and cytochemical staining with fluorophore-conjugated lectin, which showed that its expression was already observable in oocytes and their zona pellucida (ZP), likely because of maternally accumulated products [26]. $\alpha$-GalT mRNA (generated from the embryonic genome) is detectable throughout the embryonic cleavage stage and reaches peak expression during the blastocyst stage [26]. However, our previous experiment using $\alpha$-Gal epitope negative cells as a somatic cell nuclear transfer (SCNT) donor demonstrated that $\alpha$-Gal epitope expression detected by staining with a fluorophore-conjugated IB4 was almost diminished in both ZP and embryo itself in the 
SCNT-derived blastocysts [27], which suggested the disappearance of the accumulation of the maternally inherited $\alpha$-Gal epitope in the cytoplasm of embryo and ZP, during embryogenesis and up to the blastocyst stage. This unique detection system using a fluorophore-conjugated IB4 is beneficial to researchers, since the consequence of CRISPR/Cas9-mediated genome editing can be visualized as a loss of the $\alpha$-Gal epitope from the blastocyst surface. In our previous study, we injected mRNA CRISPR/Cas 9 components targeted to the porcine $\alpha$-GalT gene (GGTAl) into parthenogenetic oocytes immediately after electric activation, and found that genome editing was indeed successful, although its mode was mosaic and its frequency appeared to be low (50\%) [28].

There are several factors affecting the genome editing efficiency of zygote injection experiments, apart from appropriate gRNA selection. For example, there may be a particular mRNA concentration that confers the greatest

10 target gene KO efficiency. Furthermore, there may be a particular zygotic injection time that permits the greatest KO efficiency. In the previous successful KO piglet studies [19,20], mRNA was injected into in vivo-fertilized oocytes collected from females the day after insemination or in vitro-fertilized (IVF) oocytes at $14 \mathrm{~h}$ post-fertilization, suggesting that injection during the pronuclear stage may be suitable. Therefore, in this study, we injected mRNA into porcine oocytes $6 \mathrm{~h}$ after electric activation, when most oocytes should contain pronuclei [29], to assess whether this improved the rate of successful genome editing.

\section{Materials \& methods}

The experiments described were performed in accordance with the guidelines of Kagoshima University

20 Committee on Recombinant DNA Security and approved by the Animal Care and Experimentation Committee of Kagoshima University (no. S28003; $16^{\text {th }}$ May, 2016).

\subsection{Experimental outline}

25 An outline of this study is shown in Fig. 1A. We chose parthenogenetically activated (PA) porcine oocytes that had been electrically activated because they develop normally in vitro, like the IVF porcine oocytes [30]. Immediately after electrical activation, CRISPR/Cas9-related mRNA + enhanced green fluorescent protein (EGFP) mRNA was injected into the cytoplasm of oocytes (control group; Cont), which were then cultured in vitro for $7 \mathrm{~d}$ to reach the blastocyst stage. In the experimental (Exp) group, the PA oocytes were cultured for $6 \mathrm{~h}$ after

30 electrical activation, and then injected with the same mRNAs described above. The injected oocytes were treated as shown for the Cont group. The development rates of the injected oocytes to the 2-cell and blastocyst stages were recorded for each group. All resulting blastocysts were fixed and stained red with Alexa Fluor 594-labeled IB4 (AF594-IB4), which can specifically bind to the $\alpha$-Gal epitope [25]. Thus, it is likely that blastocysts with EGFP-derived fluorescence may also have exhibited decreased $\alpha$-Gal epitope expression due to

35 CRISPR/Cas9-mediated disruption of the $\alpha$-GalT gene. However, blastocysts without any EGFP-derived fluorescence would exhibit normal AF594-IB4 staining, since they may have lost the injected mRNA and therefore had no target gene mutations. After fluorescence photography, each blastocyst was transferred to a small tube and lysed to isolate genomic DNA, which was subjected to whole genome amplification (WGA) for a T7E1-based assay and sequencing, as detailed below.

40

\subsection{Preparation of mRNAs for microinjection}

All CRISPR/Cas9 components were the same as reported in our previous paper [27]. For Cas9 expression in mammalian cells, we used a plasmid encoding humanized Cas9, a gift from George Church (Addgene plasmid \# 41815) [31]. The plasmid for gRNA\#3 (pgRNA\#3) was used to target a sequence spanning ATG in exon 4 of 
GGTA1 (Fig. 1B; $[27,28])$. In this plasmid, poly(A) tail (T stretches) is present immediately downstream of the site (to which the gRNA sequence is inserted) to ensure stability of the resulting gRNA itself.

To prepare in vitro synthesized Cas 9 and EGFP mRNA, the Cas 9 coding sequence and EGFP cDNA in pEGFP-N1 (Invitrogen, Carlsbad, CA, USA) with poly(A) sequence were cloned into the pBluescript II plasmid (Stratagene, La Jolla, CA, USA), which contains a T7/T3 promoter for in vitro transcription. The resulting plasmids were linearized by Sap I, and in vitro transcribed by T3 mMESSAGE mMACHINE kit (\#AM1348; Ambion, Austin, TX, USA) according to the manufacturer's instructions. The gRNA\#3 plasmid was PCR-amplified with a3GalTt7-SF (5'-AGTAATACGACTCACTATAGGGAGAAAATAATGAATGTC-3') and gRNA-SR (5'AAAAAAAGCACCGACTCGGTGCCACTTTTTCAAGT-3') by using KOD-plus (\#KOD-201; Toyobo Co,

10 Osaka, Japan). The synthetic gRNA was transcribed from the template using the T7 mMESSAGE mMACHINE kit (\#AM1347; Ambion). Prepared RNAs were purified using the MEGAclear Kit (\#AM1908; Ambion) and recovered in RNase-free HEPES-buffered saline (\#H3537; Sigma-Aldrich Co., St. Louis, MO, USA). Finally, the RNA product was checked prior to the microinjection by electrophoresis on a 1 or $2 \%$ agarose gel containing formalin, using 3-( $N$-morpholino)propanesulfonic acid (MOPS) buffer (Fig. 1C).

15

\subsection{Isolation of porcine oocytes, in vitro maturation, and electric activation}

Porcine oocytes were prepared as previously described by Himaki et al. [32]. Briefly, ovaries were collected from prepubertal gilts at a local slaughterhouse and transported to the laboratory. Cumulus oocyte complexes (COCs) were aspirated from 2 to $5 \mathrm{~mm}$ diameter antral follicles with an 18 gauge needle (Terumo, Tokyo, Japan) and fixed to a $5 \mathrm{~mL}$ disposable syringe (Nipro, Osaka, Japan). The COCs were washed 3 times washed twice with HEPES (Nacalai Tesque, Kyoto, Japan)-buffered Tyrode-lactate-pyruvate-polyvinyl alcohol (HEPES-TLP-PVA) (PVA; Sigma-Aldrich Co.), and 40-50 COCs were transferred to $200 \mu \mathrm{L}$ of the maturation medium in a $35 \mathrm{~mm}$ dish (\#1008; Becton Dickinson, Franklin Lakes, NJ, USA) and pre-equilibrated at $38.5^{\circ} \mathrm{C}$ in an atmosphere of $5 \%$

$25 \mathrm{CO}_{2}$ overnight. The maturation medium contained 90\% (v/v) TCM-199 with Earle's salts (Gibco BRL, Grand Island, NY, USA), supplemented with $0.91 \mathrm{mM}$ sodium pyruvate (Sigma-Aldrich Co.), $3.05 \mathrm{mM}$ D-glucose (Wako Pure Chemical, Osaka, Japan), $0.57 \mathrm{mM}$ cysteine hydrochloride hydrate (Sigma-Aldrich Co.), $10 \mathrm{ng} / \mathrm{mL}$ epidermal growth factor (Sigma-Aldrich Co.), $10 \mathrm{IU} / \mathrm{mL}$ eCG (Aska Pharmaceutical Co., Tokyo, Japan), $10 \mathrm{IU} / \mathrm{mL}$ hCG (Aska Pharmaceutical Co.), $100 \mu \mathrm{g} / \mathrm{mL}$ amikacin sulfate (Meiji Seika, Tokyo, Japan), 0.1\% (w/v) PVA, and

$3010 \%(\mathrm{v} / \mathrm{v})$ pig follicular fluid that had been covered with paraffin oil (Nacalai Tesque). After $42-44 \mathrm{~h}$ of maturation culture, the cumulus cells were removed by pipetting with $0.1 \%(\mathrm{w} / \mathrm{v})$ hyaluronidase (Sigma-Aldrich Co.). Oocytes with a polar body were selected for the experiments.

For PA oocyte production, denuded oocytes (20-40) were placed between two wire electrodes $1 \mathrm{~mm}$ apart in activation medium (250.3 $\mathrm{mM}$ sorbitol, $0.5 \mathrm{mM} \mathrm{Ca}\left(\mathrm{CH}_{3} \mathrm{COO}\right)_{2}, 0.5 \mathrm{mM} \mathrm{Mg}\left(\mathrm{CH}_{3} \mathrm{COO}\right)_{2}$, and $0.1 \% \mathrm{BSA}$ ) [32].

35 Activation was induced with one direct current pulse of $100 \mathrm{~V} / \mathrm{mm}$ for $50 \mu \mathrm{s}$ using an LF 101 Fusion Machine (Nepa Gene Co., Chiba, Japan).

\subsection{Cytoplasmic microinjection}

40 Activated oocytes were transferred to HEPES-TLP-PVA and then subjected to a single $2 \mathrm{pL}$ cytoplasmic injection of $120 \mathrm{ng} / \mu \mathrm{L}$ humanized Cas $9 \mathrm{mRNA}, 50 \mathrm{ng} / \mu \mathrm{L}$ gRNA, and $120 \mathrm{ng} / \mu \mathrm{L}$ EGFP mRNA. Successful injection was confirmed by a slight swelling of the oocyte cytoplasm. The injected oocytes were cultured in a drop $(50 \mu \mathrm{L})$ of modified PZM-3 (mPZM-3) medium [33] containing $0.5 \mu \mathrm{M}$ latrunculin A (LatA) (\# L5163; Sigma-Aldrich Co.) for $2 \mathrm{~h}$ at $38.5^{\circ} \mathrm{C}$ to increase their in vitro developmental rate [32]. After washing with mPZM-3 medium three times, these oocytes were cultured in mPZM-3 medium under an atmosphere of 5\% 
$\mathrm{CO}_{2} / 5 \% \mathrm{O}_{2} / 90 \% \mathrm{~N}_{2}$ at $38.5{ }^{\circ} \mathrm{C}$. Cleavage and blastocyst formation were evaluated on days 2 and 7 of culture, respectively.

The developing blastocysts were then fixed for $5 \mathrm{~min}$ at room temperature in $4 \%$ paraformaldehyde in phosphate-buffered saline (PBS), $\mathrm{pH}$ 7.4, prior to fluorescence observation and subsequent lysis, as mentioned

5 below.

\subsection{Genomic DNA isolation, WGA, and PCR}

The fixed single blastocyst was transferred to a PBS drop $(1 \mu \mathrm{L})$ in a $0.5 \mathrm{~mL}$ PCR tube (\#PCR-05-C.; AxyGen Scientific, Inc., Union City, CA, USA) with the aid of a mouth-piece-controlled micropipette. Genomic DNA was extracted by adding $20 \mu \mathrm{L}$ of lysis buffer $[0.125 \mu \mathrm{g} / \mathrm{mL}$ of Proteinase $\mathrm{K}, 0.125 \mu \mathrm{g} / \mathrm{mL}$ of Pronase E, $0.32 \mathrm{M}$ sucrose, $10 \mathrm{mM}$ Tris- $\mathrm{HCl}(\mathrm{pH} 7.5), 5 \mathrm{mM} \mathrm{MgCl}$, and $1 \%$ (v/v) Triton X-100] to the blastocyst-containing drop and incubating for 2-3 days at $37^{\circ} \mathrm{C}$, followed by extraction with phenol/chloroform [28]. The supernatant was then ethanol-precipitated with the aid of the GenTLE® Precipitation Carrier (\#9094; Takara Bio, Inc., Ötsu, Japan). The precipitated DNA was dissolved in $20 \mu \mathrm{L}$ of sterile water. The DNA was stored at $4{ }^{\circ} \mathrm{C}$.

To increase the amount of whole genomic DNA, we employed WGA using Illustra GenomiPhi V2 DNA Amplification Kit (\#25-6600-31; GE Health Care Japan, Tokyo, Japan), as previously described [34]. Briefly, $2 \mu \mathrm{L}$ of genomic DNA was mixed with $8 \mu \mathrm{L}$ reaction buffer, containing the enzyme in a $20 \mu \mathrm{L}$ volume, and was then allowed to react overnight at $30{ }^{\circ} \mathrm{C}$. The resulting WGA products $(2 \mu \mathrm{L})$ were subjected to the $1^{\text {st }} \mathrm{PCR}$ using the primer set Ex4-S (5'-GCAAATTAAGGTAGAACGCA-3') and Ex4-RV (5'-GCTGCCCCTGAGCCACAACG-3') (Fig. 1B) in a volume of $20 \mu \mathrm{L}$, using the PCR conditions previously described [28]. As controls, genomic DNA ( $\sim 5 \mathrm{ng})$ isolated from normal porcine embryonic fibroblasts (PEFs) [27] were concomitantly PCR-amplified. Next, nested PCR was performed using $2 \mu \mathrm{L}$ of the $1^{\text {st }}$ PCR products and the primer set Ex4-2S (5'-CTCCTTAGCGCTCGTTGGCT-3') and Ex4-2RV (5'-GCAACTCTCTGGAATGCTTT-3') (Fig. 1B) in a $20 \mu \mathrm{L}$ volume using the same PCR conditions as the $1^{\text {st }} \mathrm{PCR}$. The resulting product is $\sim 350 \mathrm{bp}$. One microliter of the PCR products was checked via electrophoresis on a $2 \%$ agarose gel. The remaining products were then ethanol-precipitated and re-suspended in $\sim 20 \mu \mathrm{L}$ of sterile water, and the DNA concentration was measured using a spectrophotometer.

\subsection{T7E1-based assay and sequencing}

30

For the T7E1-based cleavage assay, $10 \mu \mathrm{L}$ of $1 \times$ NEB2 reaction buffer (New England BioLabs Japan Inc., Tokyo, Japan) containing $400 \mathrm{ng}$ of the nested PCR products derived from the experimental sample (200 ng derived from a blastocyst developed from an mRNA-injected oocyte) and control sample (200 ng derived from normal PEFs) were placed in a $0.5 \mathrm{~mL}$ PCR tube (AxyGen Scientific, Inc.). The PCR tube was incubated at $95{ }^{\circ} \mathrm{C}$ for $5 \mathrm{~min}$ using a thermal cycler (PC-708; Astec, Fukuoka, Japan) to denature the sample and then incubated for $0.5-1 \mathrm{~h}$ at room temperature $\left(24^{\circ} \mathrm{C}\right)$ to allow for re-annealing and to generate heteroduplex DNA. Next, $1 \mu \mathrm{L}$ of T7E1 $(2.5 \mathrm{U} / \mu \mathrm{L}$; New England BioLabs Japan Inc.) was added to the denatured/re-annealed sample, and the PCR tube was incubated at $37^{\circ} \mathrm{C}$ for $1 \mathrm{~h}$. The nuclease-treated solutions were electrophoresed on a $2 \%$ agarose gel, and the gel was stained with ethidium bromide and photographed under ultraviolet illumination.

40 For sequencing, some of the nested PCR products $\sim 350 \mathrm{bp}$ in length were first subjected to direct sequencing using the E-S primer (5'-AGATATTGGTATAAGCACTTC-3') (Fig. 1B). Furthermore, some of these PCR products were sub-cloned into the TA cloning vector pCR2.1 (Invitrogen) for sequencing. The resulting clones were subjected to sequencing using the E-S primer. Direct sequencing using dye termination cycle sequencing was performed at FASMAC Co., Ltd. (Atsugi, Kanagawa, Japan). 
Sato et al.

\subsection{Staining with AF594-IB4, detection of fluorescence, and fluorescence analysis}

The protocol for blastocyst staining with AF594-IB4 (\#I21413; Invitrogen) was described in our previous paper [27]. The stained blastocysts were examined under a fluorescence microscope (BX60; Olympus, Tokyo, Japan) using DM505 (BP460-490 and BA510IF; Olympus) and DM600 filters (BP545-580 and BA6101F; Olympus), which were used to detect EGFP-derived green fluorescence and AF594-derived red fluorescence, respectively. Micrographs were taken using a digital camera (FUJIX HC-300/OL; Fuji Film, Tokyo, Japan) attached to the fluorescence microscope, and images were printed using a Mitsubishi digital color printer (CP700DSA; Mitsubishi, Tokyo, Japan).

10 In some cases, the strength of the EGFP-derived fluorescence (luminance) in single blastocysts was measured in candelas per square meter $\left(\mathrm{cd} / \mathrm{m}^{2}\right)$ using a tool (NIS-Elements; Nikon Co., Tokyo, Japan).

\subsection{Examination of nuclear status in PA oocytes}

15 To examine the nuclear status in PA oocytes after cytoplasmic injection, oocytes were first fixed with $25 \%(\mathrm{v} / \mathrm{v})$ acetic acid in ethanol for 48-72 $\mathrm{h}$ at room temperature immediately or $6 \mathrm{~h}$ after electrical activation, and then subjected to staining with $1 \%(\mathrm{w} / \mathrm{v})$ orcein in $45 \%(\mathrm{v} / \mathrm{v})$ acetic acid. The images were captured using the Nomarski differential interference microscope (Olympus).

\subsection{Statistics}

Data are presented as mean \pm standard error (SE). All percentage data were subjected to arcsine transformation for each replicate. The transformed values and the strength of EGFP-derived fluorescence were analyzed using one-way ANOVA followed by Fisher's protected least significant difference test. A probability of $p<0.05$ was considered statistically significant.

\section{Results}

\subsection{Evaluating CRISPR/Cas9-based genome editing efficiency in porcine embryos}

As outlined in Fig. 1A, oocytes that were matured in vitro immediately or $6 \mathrm{~h}$ after electric activation were injected with a solution containing $\operatorname{Cas} 9$ mRNA, gRNA, and EGFP mRNA into the cytoplasm and then cultured in vitro for 7 days until the blastocyst stage. In both groups, the cleavage rate $(69.6 \%$ vs. $78.8 \%$; Table 1$)$ and blastocyst formation rate ( $46.6 \%$ vs. $48.2 \%$; Table 1$)$ were comparable to those of intact PA oocytes $(67.7 \%$ for cleavage and $33.1 \%$ for blastocyst formation; [32]). Thus, the timing of the RNA injection does not appear to be a critical factor for porcine embryonic development.

After briefly fixing all the developing blastocysts and subsequently staining with AF594-IB4, both EGFP-derived green and AF594-derived red fluorescence was examined under a fluorescence microscope. Notably, the number of green fluorescent blastocysts derived from oocytes injected $6 \mathrm{~h}$ after activation (Exp group)

40 was significantly higher $(p<0.05)$ than that of the blastocysts derived from oocytes injected immediately after activation (Cont group) (Exp vs. Cont, "EGFP" column of Fig. 2A; 77.8\% vs. 41.6\%, left panel of Fig. 2B). Furthermore, the intensity of green fluorescence in the Exp group was significantly higher $(p<0.05)$ than in the Cont group (30.7 vs. 8.1, right panel of Fig. 2B). Unfortunately, the green fluorescent blastocysts in both groups, which were hypothesized to have successfully disrupted the GGTA1 target gene [28], were all positive for the AF594-IB4 stain ("AF594-IB4" column of Fig. 2A), suggesting that in these green fluorescent blastocysts, almost 
all the cells were mono-allelic knockout (KO) cells (positive for $\alpha$-Gal expression) or wild-type cells (positive for $\alpha$-Gal expression). Thus, even if biallelic KO cells (complete loss of $\alpha$-Gal expression) were present in these embryos, there would only be a few in the blastocyst.

Next, we performed molecular analyses to determine whether these green fluorescent blastocysts possessed indels at the target locus. Exp group embryos (29 green fluorescent and 5 non-fluorescent embryos) were lysed and genomic DNA was isolated. As shown in Fig. 1A, we employed WGA to amplify the whole genome of a single blastocyst prior to direct PCR-based amplification of the target locus. According to our previous data, approximately 84 ng of genomic DNA can be obtained per blastocyst [34]. When PCR ( $1^{\text {st }}$ and nested) was performed using WGA products as the template, all the samples successfully yielded distinct $\sim 350$ bp products, which corresponded to the region spanning the target site (data not shown). Using these WGA/PCR-based amplified samples, we performed a T7E1-based cleavage assay. A representative example is shown in Fig. 3A. Sixty-nine percent (20/29) of the green fluorescent blastocysts derived from parthenotes at $6 \mathrm{~h}$ after the activation had two cleaved bands at $\sim 200$ and $\sim 150$ bp, together with $\sim 350$-bp products (lanes $1-4,10,12-14,17$, and 19-21 in Fig. 3A; Table 2), which indicated that they contained both mutant (monoallelic and biallelic $\mathrm{KO}$ cells) and wild-type cells. In contrast, non-green fluorescent blastocysts had no cleaved bands (lanes 5-9, Fig. 3A), which suggested that they contained wild-type cells. This was also supported by cytochemical AF594-IB4 staining, which showed that these blastocysts were uniformly labeled ("Exp" in Fig. 2A; Table 2). In contrast, 38\% of the green fluorescent blastocysts derived from parthenotes at $0 \mathrm{~h}$ after the activation exhibited indels (lanes 23, 24, 29, 33 and 34 shown in Fig. 3A; Table 2). Similar to the "Exp" group, all blastocysts in "Cont" were positively stained with

20 AF594-IB4 ("Cont" in Fig. 2A; Table 2). To further examine the location of indels in GGTA1, the 350-bp PCR products obtained from three blastocysts (lanes 1-3 in Fig. 3A), together with the control samples (products from intact PEFs; lane $\mathrm{C}$ in Fig. 3A), were subjected to direct sequencing by using the E-S primer (corresponding to the sequence upstream of the GGTA1 start codon; Fig. 1B). As predicted, there were disordered ideograms downstream of the start codon (indicated by "start of error ideograms" in Fig. 3B) in all the samples that had cleaved bands in the T7E1 assay, indicating the presence of multiple (at least one) mutations. In contrast, no disordered ideograms were noted in the control samples ("Wild-type PEFs" in Fig. 3B). To further examine the mutation types present in the green fluorescent blastocysts, the $\sim 350 \mathrm{bp}$ PCR products from the samples shown in lanes 1 to 3 of Fig. $3 \mathrm{~A}$ were cloned into a TA cloning vector, and randomly selected $E$. coli transformants were sequenced using the E-S primer. As a result, there were more than 2 clone types for each blastocyst (Fig. 3C). These clones contained indel and wild-type sequences at various ratios. For examples, in blastocyst \#1, 4 clones had mutated sequences with an identical mutation pattern, while 1 clone had the normal sequence. Similarly, in blastocyst \#3, there were clones with at least 2 indel types (both had an inserted sequence comprising 5 nucleotides downstream of the start codon, but also had one or two nucleotide substitutions) and those with wild-type sequence.

In the above experiments, we found that mRNA injection $6 \mathrm{~h}$ (but not immediately) after oocyte activation resulted in good mRNA-translated protein expression, at least when expression of EGFP-derived fluorescence was monitored. After activation, the chromosomes are thought to be re-programmed before pronuclear formation [35],

40 meaning that pronuclear formation in oocytes does not fully proceed in the immediate post-activation stage, but becomes visible during development. To examine this, we stained fixed oocytes immediately or $6 \mathrm{~h}$ after activation using the aceto-orcein staining method. Of the 16 oocytes stained immediately after activation, none exhibited pronuclear formation (Fig. $4 \mathrm{a}-\mathrm{c}$ ). In contrast, 14 of the 15 oocytes stained $6 \mathrm{~h}$ after activation exhibited clear formation of a pronucleus (arrows in Fig. 4d-f). 
Sato et al.

\section{Discussion}

To date, direct zygotic injection of CRISPR/Cas9-related mRNA has been recognized as a powerful technique for biallelic $\mathrm{KO}$ animal production, including swine [2]. However, confirming the presence of indels induced by this genome editing system has typically been performed using the resulting fetuses or newborns, which is time-consuming and labor-intensive. Notably, Sakurai et al. [21] and Wang et al. [36] demonstrated the usefulness of the T7E1 assay for indel detection in individual blastocysts. This approach allows researchers to test the genome editing efficiency of constructed gRNAs in early embryos, thus saving time and money. This assay advantageously allows one to examine the consequences of a targeted gene $\mathrm{KO}$, as protein products are expressed on the blastocyst surface. In this study, we intended to disrupt GGTA1, which encodes a protein product that synthesizes the $\alpha$-Gal epitope [22], which is easily detectable by staining cells/embryos with fluorescently labeled IB4 lectin [24,25]. This detection system, based on the loss of cell surface $\alpha$-Gal epitope expression, enables us to assess the consequence of CRISPR/Cas9-mediated genome editing at early stages of embryonic development. Unfortunately, all the resulting blastocysts expressed the $\alpha$-Gal epitope ubiquitously (see Fig. 2A). These data suggest that the mRNA for the introduced CRISPR/Cas9 components were not efficacious in porcine oocytes, although the mRNA for EGFP, which had been concomitantly introduced, was functionally translated into protein. However, almost all the tested green fluorescent blastocysts exhibited indels, as revealed by the T7E1 assay (see Fig. 3A). Furthermore, sequencing revealed a mosaic of mutations at the target locus, as demonstrated by the presence of error ideograms immediately downstream of the start codon (see Fig. 3B), as well as at least one mutation type (see Fig. 3C). It remains unknown why such mosaicism frequently occurs in our system. Notably, there are some reports where zygote-derived embryos injected with exogenous materials are often found to be edited in a mosaic pattern [20,28,37,38]. According to Burkard et al. [38], such mosaicism appears to be due to Cas9 protein/gRNA complexes that remain active throughout several cell divisions, or delayed mRNA expression, possibly triggered by cell division. In this context, injection of Cas9/gRNA ribonucleoproteins (RNPs) may be helpful in overcoming such mosaicism, since RNPs are thought to exhibit more rapid and efficient genome editing activity than Cas9 mRNA and gRNA [39,40].

Notably, off-target mRNA is also a serious concern when utilizing a CRISPR/Cas9 system for mutation induction at a target locus. In our previous study, we assessed this problem and found that microinjection of CRISPR/Cas9-related mRNA resulted in successful genome editing at the target locus (i.e., GGTAl coding for $\alpha$-GalT), but did not induce any mutation in the related genes [28].

Aside from the selection of appropriate gRNA, there are several other factors affecting mutation efficiency for zygote (oocyte) injection-based genome editing. One of these factors is the time at which the oocyte injection is performed. In this study's Cont group, in which oocyte injection was performed immediately after activation, the rate of green fluorescent blastocysts was low when compared to the blastocysts in the Exp group, which had been injected $6 \mathrm{~h}$ after activation (see Fig. 2A; left panel of Fig. 2B). Furthermore, the intensity of the EGFP-derived fluorescence was higher in the Exp group (see Fig. 2A; right panel of Fig. 2B). These data suggest that mRNA may have been actively used for protein synthesis in the oocytes injected $6 \mathrm{~h}$ after activation. We hypothesized that these observed phenomena may correlate with the formation of the pronucleus. We performed aceto-orcein staining and showed that oocytes injected immediately after activation did not have distinct pronuclei, whereas those injected 6

$40 \mathrm{~h}$ after activation did (see Fig. 4). At present, it is unknown if the formation of the pronucleus correlates with increased mRNA translation. However, according to Alberts et al. [41], the outer nuclear membrane is studded with ribosomes involved in protein synthesis, suggesting a close association between nuclear membrane formation and protein synthesis. Our present results indicated that injection of the oocyte $6 \mathrm{~h}$ after parthenote or SCNT embryo activation, or $6 \mathrm{~h}$ after fertilization of IVF embryos is ideal. Although zygote microinjection-based genome editing using ZFN, TALEN, and CRISPR/Cas9 systems has been performed in swine by several laboratories 
$[7,19,20,36,42,43]$, there is limited information regarding the timing of zygotic genome editing component microinjection. For example, Wang et al. [44] injected TALEN mRNA and EGFP mRNA into zygotes obtained 6 $\mathrm{h}$ after IVF. More interestingly, Tao et al. [45] performed cytoplasmic injections in porcine PA oocytes $8 \mathrm{~h}$ after activation and achieved biallelic mutations (93\%) and low mosaicism (33\%). These reports appear to validate our present findings.

Our present concern is evaluating whether porcine zygotes injected with CRISPR/Cas9 component mRNAs can develop to full-term with a high degree of genome editing efficiency. Hai et al. [19] microinjected mRNA into zygotes isolated from pregnant females and then returned the injected zygotes to the oviducts of the same females, which is technically difficult due to the need for labor and an appropriate number of recipient pigs. Whitmuth et al.

10 [20] used in vitro fertilized porcine oocytes microinjected with mRNA. Even in this case, oocytes from a specific strain, and sperm derived from viable males or frozen stock are needed, which is also laborious. The ideal, convenient approach would involve SCNT using intact cells as donors and subsequent injection of the SCNT embryos with mRNA. The porcine ovary, from which the oocytes are isolated, can be easily obtained from a slaughterhouse. Recently, we have established an efficient SCNT protocol for cloned microminipig production, using oocytes isolated from slaughterhouse ovaries [46]. Since the phenotype of cloned piglets is governed by that of the donor cells, sperm or oocytes from specific males and females bred in-house are not always required. This point is especially advantageous for researchers who do not have the capacity to breed many animals in their facility. In the future, we plan to clone swine with target locus mutations by microinjecting SCNT embryos (produced using intact cells as donors) with CRISPR/Cas9 component mRNAs $6 \mathrm{~h}$ after electrical activation.

\section{Conclusions}

In this study, when cytoplasmic injection of CRISPR/Cas9-related mRNA was performed on porcine oocytes 6 $\mathrm{h}$ after electrical activation, we successfully obtained blastocysts with a relatively high frequency of genome editing. However, these blastocysts tended to exhibit mutation induction mosaicism, as revealed by cytochemical staining with fluorescently labeled IB4, the T7E1 assay, and sequencing. Development of a technique that avoids or reduces such mosaicism would be a key factor in allowing efficient production of KO piglets via zygotic injection.

\section{Acknowledgements}

This study was partly supported by a grant (no. 24580411 for M.S.; nos. 25450475 and 16K08085 for K.M.) from The Ministry of Education, Science, Sports, and Culture, Japan.

\section{Author Contributions}

35

M.S. designed the study, analyzed the data, and drafted the manuscript. M.K., Ko.M. and Ka.M. performed mRNA microinjection experiments. S.W. prepared mRNA used for injection. M.O., T.S., and S.N. were involved in the molecular biology analyses of PCR-amplified products. E.I. and I.S. critically revised the manuscript.

\section{Conflict of interest}

None of the authors have any conflict of interest to declare. 
Sato et al.

\section{References}

[1] Hsu PD, Scott DA, Weinstein JA, Ran FA, Konermann S, Agarwala V, Li Y, Fine EJ, Wu X, Shalem O, Cradick TJ, Marraffini LA, Bao G, Zhang F. DNA targeting specificity of RNA-guided Cas9 nucleases. Nat Biotechnol 2013;31:827-32. DOI: 10.1038/nbt.2647.

[2] Harrison MM, Jenkins BV, O’Connor-Giles KM, Wildonger J. A CRISPR view of development. Genes Dev 2014;28:1859-72. doi: 10.1101/gad.248252.114.

[3] Horvath PR, Barrangou R. CRISPR/Cas, the immune system of bacteria and archaea. Science 2010;327: 167-70. doi: 10.1126/science.1179555.

10 [4] Bhaya D, Davison M, Barrangou R. CRISPR-Cas systems in bacteria and archaea: versatile small RNAs for adaptive defense and regulation. Ann Rev Genet 2011;45:273-97. doi: 10.1146/annurev-genet-110410-132430.

[5] Jinek M, Chylinski K, Fonfara I, Hauer M, Doudna JA, Charpentier E. A programmable dual-RNA-guided DNA endonuclease in adaptive bacterial immunity. Science 2012;337:816-21. doi: 10.1126/science.1225829.

[6] Hsu PD, Lander ES, Zhang F. Development and applications of CRISPR-Cas9 for genome engineering. Cell 2014;157:1262-78. doi: 10.1016/j.cell.2014.05.010.

[7] Carlson DF, Fahrenkrug SC, Hackett PB. Targeting DNA with fingers and TALENs. Mol Ther Nucleic Acids 2012;1:e3. doi: 10.1038/mtna.2011.5.

[8] Doench JG, Hartenian E, Graham DB, Tothova Z, Hegde M, Smith I, Sullender M, Ebert BL, Xavier RJ, Root DE. Rational design of highly active sgRNAs for CRISPR-Cas9-mediated gene inactivation. Nat Biotechnol

$20 \quad$ 2014;32:1262-7. doi:10.1038/nbt.3026.

[9] Fu Y, Sander JD, Reyon D, Cascio VM, Joung JK. Improving CRISPR-Cas nuclease specificity using truncated guide RNAs. Nat Biotechnol 2014;32:279-84. doi: 10.1038/nbt.2808.

[10] Koike-Yusa H, Li Y, Tan EP, Velasco-Herrera Mdel C, Yusa K. Genome-wide recessive genetic screening in mammalian cells with a lentiviral CRISPR-guide RNA library. Nat Biotechnol 2014;32:267-73. doi:

$25 \quad 10.1038 /$ nbt.2800.

[11] Yang H, Wang H, Shivalila CS, Cheng AW, Shi L, Jaenisch R. One-step generation of mice carrying reporter and conditional alleles by CRISPR/Cas-mediated genome engineering. Cell 2013;154:1370-9. doi: 10.1016/j.cell.2013.08.022.

[12] Wang H, H. Yang H, Shivalila CS, Dawlaty MM, Cheng AW, Zhang F, Jaenisch R. One-step generation of mice carrying mutations in multiple genes by CRISPR/Cas-mediated genome engineering. Cell 2013;153:910-8. http://dx.doi.org/10.1016/j.cell.2013.04.025.

[13] Li W, Teng F, Li T, Zhou Q. Simultaneous generation and germline transmission of multiple gene mutations in rat using CRISPR-Cas systems. Nat Biotechnol 2013;31:684-6. doi: 10.1038/nbt.2652.

[14] Fujii W, Kawasaki K, Sugiura K, Naito K. Efficient generation of large-scale genome-modified mice using gRNA and CAS9 endonuclease. Nucl Acids Res 2013;41:e187. doi: 10.1093/nar/gkt772.

[15] Shen B, Zhang J, Wu H, Wang J, Ma K, Li Z, Zhang X, Zhang P, Huang X. Generation of gene-modified mice via Cas9/RNA-mediated gene targeting. Cell Res 2013;23:720-3. doi:10.1038/cr.2013.46.

[16] Ma Y, Ma J, Zhang X, Chen W, Yu L, Lu Y, Bai L, Shen B, Huang X, Zhang L. Generation of eGFP and Cre knockin rats by CRISPR/Cas9. FEBS J 2014;281:3779-90. doi: 10.1111/febs.12935.

40 [17] Zhu X, Xu Y, Yu S, Lu L, Ding M, Cheng J, Song G, Gao X, Yao L, Fan D, Meng S, Zhang X, Hu S, Tian Y. An efficient genotyping method for genome-modified animals and human cells generated with CRISPR/Cas9 system. Sci Rep 2014;4:6420. doi:10.1038/srep06420.

[18] Niu Y, Shen B, Cui Y, Chen Y, Wang J, Wang L, Kang Y, Zhao X, Si W, Li W, Xiang AP, Zhou J, Guo X, Bi Y, Si C, Hu B, Dong G, Wang H, Zhou Z, Li T, Tan T, Pu X, Wang F, Ji S, Zhou Q, Huang X, Ji W, Sha J. Generation of gene-modified cynomolgus monkey via Cas9/RNA-mediated gene targeting in one-cell 
embryos. Cell 2014;156:836-43. doi: 10.1016/j.cell.2014.01.027.

[19] Hai T, Teng F, Guo R, Li W, Zhou Q. One-step generation of knockout pigs by zygote injection of CRISPR/Cas system. Cell Res 2014;24:372-5. doi:10.1038/cr.2014.11.

[20] Whitworth KM, Lee K, Benne JA, Beaton BP, Spate LD, Murphy SL, Samuel MS, Mao J, O'Gorman C, Walters EM, Murphy CN, Driver J, Mileham A, McLaren D, Wells KD, Prather RS. Use of the CRISPR/Cas9 system to produce genetically engineered pigs from in vitro-derived oocytes and embryos. Biol Reprod 2014;91:78. doi: 10.1095/biolreprod.114.

[21] Sakurai T, Watanabe S, Kamiyoshi A, Sato M, Shindo T. A single blastocyst assay optimized for detecting CRISPR/Cas9 system-induced indel mutations in mice. BMC Biotechnol 2014;14:69. DOI: 10.1186/1472-6750-14-69.

[22] Galili U. The $\alpha$-gal epitope (Gal $\alpha 1-3$ Gal $\beta 1-4 G l c N A c-R)$ in xenotransplantation. Biochimie 2001;83:557.

[23] Cooper DK., Gollackner B, Sachs DH. Will the pig solve the transplantation backlog? Ann Rev Med 2002;53: 133. DOI: 10.1146/annurev.med.53.082901.103900.

[24] Vaughan HA, Loveland BE, Sandrin MS. Gal $(\alpha 1-3)$ Gal is the major xenoepitope expressed on pig endothelial cells recognized by naturally occurring cytotoxic human antibodies. Transplantation 1994;58:879-82. PMID: 7524207.

[25] Sato M, Akasaka E, Saitoh I, Ohtsuka M, Nakamura S, Sakurai T, Watanabe S. Targeted toxin-based selectable drug-free enrichment of mammalian cells with high transgene expression. Biology 2013;2:341-55. doi: $10.3390 /$ biology2010341.

20 [26] Chi H, Sato M, Yoshida M, Miyoshi K. Expression analysis of a $\alpha-1$, 3-galactosyltransferase, an enzyme that creates xenotransplantation-related $\alpha$-Gal epitope, in pig preimplantation embryos. Anim Sci J 2012;83:88-93. DOI: 10.1111/j.1740-0929.2011.00964.X.

[27] Sato M, Miyoshi K, Nagao Y, Nishi Y, Ohtsuka M, Nakamura S, Sakurai T, Watanabe S. The combinational use of CRISPR/Cas9-based gene editing and targeted toxin technology enables efficient biallelic knockout of the $\alpha$-1,3-galactosyltransferase gene in porcine embryonic fibroblasts. Xenotransplantation 2014;21:291-300. doi: $10.1111 /$ xen.12089.

[28] Sato M, Koriyama M, Watanabe S, Ohtsuka M, Sakurai T, Inada E, Saitoh I, Nakamura S, Miyoshi K. Direct injection of CRISPR/Cas9-related mRNA into cytoplasm of parthenogenetically activated porcine oocytes causes frequent mosaicism for indel mutations. Int J Mol Sci 2015;16:17838-56. doi: $30 \quad 10.3390 /$ ijms160817838.

[29] Sato K, Yoshida M, Miyoshi K. Utility of ultrasound stimulation for activation of pig oocytes matured in vitro. Mol Reprod Dev 2005;72:396-403. doi: 10.1002/mrd.20352.

[30] Kure-bayashi S, Miyake M, Katayama M, Miyano T, Kato S. Development of porcine blastocysts from in vitro-matured and activated haploid and diploid oocytes. Theriogenology 1996;46:1027-36.

35 [31] Mali P, Yang L, Esvelt KM, Aach J. RNA-guided human genome engineering via Cas9. Science 2013;339:823-6. doi: 10.1126/science.1232033.

[32] Himaki T, Mizobe Y, Tsuda K, Suetomo M, Yamakuchi H, Miyoshi K, Takao S, Yoshida M. Effect of postactivation treatment with latrunculin A on in vitro and in vivo development of cloned embryos derived from kidney fibroblasts of an aged Clawn miniature boar. J Reprod Dev 2012;58:398-403. http://doi.org/10.1262/jrd.11-083A.

[33] Yoshioka K, Suzuki C, Tanaka A, Anas IM, Iwamura S. Birth of piglets derived from porcine zygotes cultured in a chemically defined medium. Biol Reprod 2002;66:112-19. https://doi.org/10.1095/biolreprod66.1.112.

[34] Akasaka E, Ozawa A, Mori H, Mizobe Y, Yoshida M, Miyoshi K, Sato M. Whole-genome amplification-based GenomiPhi for multiple genomic analysis of individual early porcine embryos. Theriogenology 2011;75:1543-9. DOI: 10.1016/j.theriogenology.2010.12.018. 
Sato et al.

[35] Yin XJ, Kato Y, Tsunoda Y. Effect of delayed enucleation on the developmental potential of nuclear-transferred oocytes receiving adult and fetal fibroblast cells. Zygote 2002;10:217-22. http://dx.doi.org/10.1017/S0967199402002289.

[36] Wang X, Zhou J, Cao C, Huang J, Hai T, Wang Y, Zheng Q, Zhang H, Qin G, Miao X, Wang H, Cao S, Zhou Q, Zhao J. Efficient CRISPR/Cas9-mediated biallelic gene disruption and site-specific knockin after rapid selection of highly active sgRNAs in pigs. Sci Rep 2015;5:13348. doi:10.1038/srep13348.

[37] Lillico SG, Proudfoot C, Carlson DF, Stverakova D, Neil C, Blain C, King TJ, Ritchie WA, Tan W, Mileham AJ, McLaren DG, Fahrenkrug SC, Whitelaw CB. Live pigs produced from genome edited zygotes. Sci Rep 2013;3:2847. doi: 10.1038/srep02847.

10 [38] Burkard C, Lillico SG, Reid E, Jackson B, Mileham AJ, Ait-Ali T, Whitelaw CB, Archibald AL. Precision engineering for PRRSV resistance in pigs: Macrophages from genome edited pigs lacking CD163 SRCR5 domain are fully resistant to both PRRSV genotypes while maintaining biological function. PLoS Pathog. 2017;13:e1006206. doi: 10.1371/journal.ppat.1006206.

[39] Kim S, Kim D, Cho SW, Kim J, Kim JS. Highly efficient RNA-guided genome editing in human cells via delivery of purified Cas9 ribonucleoproteins. Genome Res 2014;24: 1012-9. doi: 10.1101/gr.171322.113.

[40] Liang X, Potter J, Kumar S, Zou Y, Quintanilla R, Sridharan M, Carte J, Chen W, Roark N, Ranganathan S, Ravinder N, Chesnut JD. Rapid and highly efficient mammalian cell engineering via Cas9 protein transfection. J Biotechnol 2015;208:44 53. doi: 10.1016/j.jbiotec.2015.04.024.

[41] Alberts B, Johnson A, Lewis J, Raff M, Roberts K, Walter P. Molecular Biology of the Cell, $4^{\text {th }}$ ed.; Garland Science: New York, USA. 2002. doi: 10.1093/aob/mcg023.

[42] Xin J, Yang H, Fan N, Zhao B, Ouyang Z, Liu Z, Zhao Y, Li X, Song J, Yang Y, Zou Q, Yan Q, Zeng Y, Lai L. Highly efficient generation of GGTA1 biallelic knockout inbred mini-pigs with TALENs. PLoS One 2013;8:e84250. doi: 10.1371/journal.pone.0084250.

[43] Zhou X, Xin J, Fan N, Zou Q, Huang J, Ouyang Z, Zhao Y, Zhao B, Liu Z, Lai S, Yi X, Guo L, Esteban MA, Zeng Y, Yang H, Lai L. Generation of CRISPR/Cas9-mediated gene-targeted pigs via somatic cell nuclear transfer. Cell Mol Life Sci 2015;72:1175-84. doi: 10.1007/s00018-014-1744-7.

[44] Wang Y, Du Y, Shen B, Zhou X, Li J, Liu Y, Wang J, Zhou J, Hu B, Kang N, Gao J, Yu L, Huang X, Wei H. Efficient generation of gene-modified pigs via injection of zygote with Cas9/sgRNA. Sci Rep 2015;5:8256. doi:10.1038/srep08256.

30 [45] Tao L, Yang M, Wang X, Zhang Z, Wu Z, Tian J, An L, Wang S. Efficient biallelic mutation in porcine parthenotes using a CRISPR-Cas9 system. Biochem Biophys Res Commun 2016;476:225-9. doi: 10.1016/j.bbrc.2016.05.100.

[46] Miyoshi K, Kawaguchi H, Maeda K, Sato M, Akioka K, Noguchi M, Horiuchi M, Tanimoto A. Birth of cloned microminipigs derived from somatic cell nuclear transfer embryos that have been transiently treated with valproic acid. Cell Reprogram 2016;18:390-400. doi:10.1089/cell.2016.0025. 
Sato et al.

Table 1

Summary of the properties of blastocysts derived from PA oocytes injected with CRISPR/Cas9-related mRNA + EGFP mRNA ${ }^{1}$.

\begin{tabular}{cccc}
\hline Stage at injection & $\begin{array}{c}\text { Total number } \\
\text { of oocytes examined }\end{array}$ & $\begin{array}{c}\text { No. of oocytes } \\
\text { cleaved to the } \\
\text { 2-cell stage } \\
(\% \text {; average } \pm \text { S.E. })\end{array}$ & $\begin{array}{c}\text { No. of oocytes } \\
\text { cleaved to } \\
\text { blastocysts } \\
(\% \text {; average } \pm \text { S.E. })\end{array}$ \\
\hline $\begin{array}{c}\text { Immediately } \\
(0 \mathrm{~h})\end{array}$ & 105 & 73 & 49 \\
$6 \mathrm{~h}$ & 127 & $(69.6 \pm 2.0)$ & $(46.6 \pm 0.7)$ \\
& & 99 & 61 \\
$(78.8 \pm 5.8)$ & $(48.2 \pm 5.2)$ \\
\hline
\end{tabular}

5 Cytoplasmic injection of Cas 9 mRNA + gRNA (targeted to exon 4 of GGTAl) + EGFP mRNA is performed on PA oocytes immediately or $6 \mathrm{~h}$ after PA. Oocytes were then cultured for 7 days to the blastocyst stage and examined for EGFP-derived fluorescence prior to fixation.

Table 2

10 Comparison of the properties of blastocysts derived from oocytes injected with CRISPR/Cas9-related components + EGFP $\mathrm{mRNA}^{1}$ between $0 \mathrm{~h}$ and $6 \mathrm{~h}$ after PA.

\begin{tabular}{|c|c|c|c|}
\hline \multirow[t]{2}{*}{ Properties } & \multicolumn{2}{|c|}{$0 \mathrm{~h}$ after $\mathrm{PA}$} & \multirow{2}{*}{$\begin{array}{c}6 \text { h after PA } \\
\text { This study } \\
\text { (Exp) }\end{array}$} \\
\hline & Sato et al. [28] & $\begin{array}{l}\text { This study } \\
\text { (Cont) }\end{array}$ & \\
\hline $\begin{array}{l}\text { Rate of EGFP } \\
\text { expression }\end{array}$ & $65 \%(24 / 37)^{3}$ & $41 \%(13 / 32)^{3, a}$ & $73 \%(29 / 40)^{3, b}$ \\
\hline Indel rate ${ }^{2}$ & $50 \%(5 / 10)^{3}$ & $38 \%(5 / 13)^{3, a}$ & $69 \%(20 / 29)^{3, b}$ \\
\hline $\begin{array}{l}\text { Rate of fluorescent } \\
\text { blastocysts that were } \\
\text { positively stained } \\
\text { with AF594-IB4 }\end{array}$ & $\begin{array}{c}100 \%(5 / 5)^{3} \text {; only one has } \\
\text { decreased staining for } \\
\text { AF594-IB4 }\end{array}$ & $100 \%(13 / 13)^{3}$ & $100 \%(29 / 29)^{3}$ \\
\hline
\end{tabular}

${ }^{1}$ Cytoplasmic injection of Cas 9 mRNA + gRNA (targeted to exon 4 of GGTA1) + EGFP mRNA was performed on PA oocytes immediately (Cont) or $6 \mathrm{~h}$ (Exp) after PA. Oocytes were then cultured for 7 days to the blastocyst

15 stage and examined for EGFP-derived fluorescence prior to fixation. Next, the fixed blastocysts were cytochemically stained using AF594-IB4, and finally, genomic DNA was isolated to examine the presence of indels.

${ }^{2}$ Indel rates were determined by the T7E1 assay and sequencing of PCR products derived from fluorescent single blastocysts. Blastocysts with at least one mutated allele were categorized as having indels.

$20{ }^{3}$ Parentheses indicates the number of blastocysts with positive results (expression of EGFP, occurrence of indels, or expression of $\alpha$-Gal epitope) per the number of the blastocysts tested.

$\mathrm{ND}$, not determined.

a-b Uppercase letters denote significant $(P<0.05)$ differences between groups in the same column. 
Sato et al.

\section{Figure legends}

Fig. 1. A. Schematic representation of a single blastocyst-based assay after isolation of porcine oocytes from an ovary, in vitro maturation, electric activation, and subsequent cytoplasmic injection with CRISPR/Cas9-related mRNA $+E G F P$ mRNA. After electric activation, porcine oocytes were divided into two groups: those that were injected immediately after electric activation (control group, Cont), and those that were injected $6 \mathrm{~h}$ after electric activation (experimental group, Exp). B. Schematic representation of the genomic sequence spanning exon 4 of the porcine GGTA1. The target sequence recognized by gRNA\#3 is indicated by a bold light blue bar beneath the sequence. The start codon is shown in red. The protospacer adjacent motif (PAM) site is underlined. Primers used for PCR and sequencing are shown and described below the GGTA1 sequence. Asterisks indicate the mutated portion in exon 4 of GGTA1. C. Gel electrophoretic pattern of in vitro synthesized Cas9 mRNA, gRNA, and EGFP mRNA. Cas9 mRNA and both gRNA and EGFP mRNA were loaded onto 1 or $2 \%$ agarose gels, respectively.

15 Fig. 2. A. Fluorescent images of single blastocysts derived from PA oocytes (parthenotes), and developed after oocyte injection with CRISPR/Cas9-related and EGFP mRNA immediately (Cont) or 6 h (Exp) after electric activation. Blastocysts were fixed for a short period, stained with AF594-IB4, and then inspected for EGFP and AF594-derived fluorescence using a fluorescence microscope. Bar $=100 \mu \mathrm{m}$. B. The rate of green fluorescent blastocysts in the Cont and Exp groups is shown graphically (left panel). The intensity of the EGFP-derived

20 fluorescence in single blastocysts from the Cont and Exp groups is shown graphically (right panel). The fluorescence intensity of each blastocyst was measured using NIS-Elements and is shown graphically. A total of 49 and 61 blastocysts in the Cont and Exp groups, respectively, were examined.

Fig. 3. A. T7E1-based assay for each single blastocyst. The $\sim 350 \mathrm{bp}$ PCR products containing the target sequence recognized by gRNA were mixed with control (C) DNA at a ratio of 1:1, denatured, re-annealed, and then incubated with the T7E1 enzyme for $1 \mathrm{~h}$ at $37^{\circ} \mathrm{C}$. The resulting products were electrophoresed in a $\%$ agarose gel. If the samples had indels, two fragments (shown by arrowheads), $\sim 200$ and $\sim 150 \mathrm{bp}$ in length, were generated as cleaved products from the original $\sim 350$ bp products. Lanes $1-4$ and 10-22 correspond to green fluorescent single blastocysts derived from the experimental (Exp) group. Lanes 5-9 correspond to non-fluorescent single blastocysts

30 derived from the Exp group. Lanes 23-35 correspond to green fluorescent single blastocysts derived from the control (Cont) group. Lane C indicates genomic DNA from normal PEFs that were used as negative controls. Lanes enclosed by the red circles indicate samples with mutations. M, 100 bp ladder markers. B. Direct sequencing of PCR products ( $\sim 350 \mathrm{bp})$ from the blastocyst and normal PEFs shown in lanes 1-3 and C of Fig. 3A. Black arrows below the DNA sequence traces show overlapping peaks caused by additional indels. Boxes indicate the translation initiation codon. C. Sequencing of the inserts derived from blastocysts in lanes 1 to 3 of Fig. 3A cloned into a TA cloning vector using the E-S primer set is shown. The start codon is underlined. The sequences inserted are marked in blue. Substitution mutations are shown in red.

Fig. 4. Aceto-orcein staining of porcine oocytes immediately (a-c) or $6 \mathrm{~h}(\mathrm{~d}-\mathrm{f})$ after electric activation. Images for three oocytes from each group are shown. Arrows indicate the nuclear envelope that developed in an oocyte. Scale bars: $30 \mu \mathrm{m}$. 

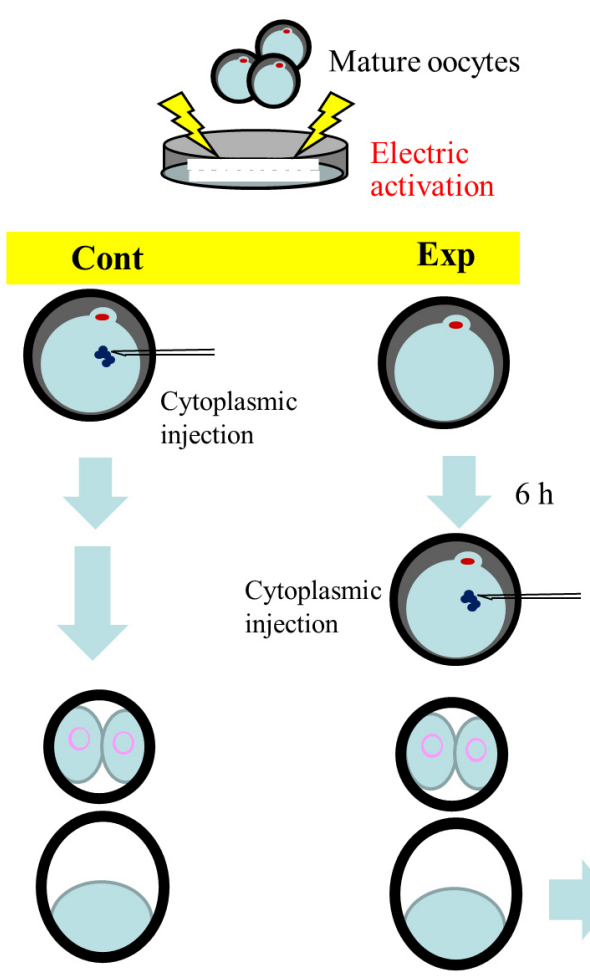

Fixation with $4 \%$ PFA

Staining with AF594-IB4

Photographing fluorescence

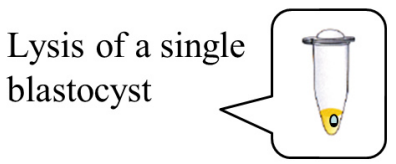

Purification of genomic DNA

Whole genome amplification PCR

T7E1 assay

Sequencing

B

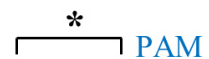

---- CTTTTCCCAG GAG AAA ATA ATG AAT GTC AA AGGAAGAGT----

C Target sequence

Porcine $\alpha$-GalT gene
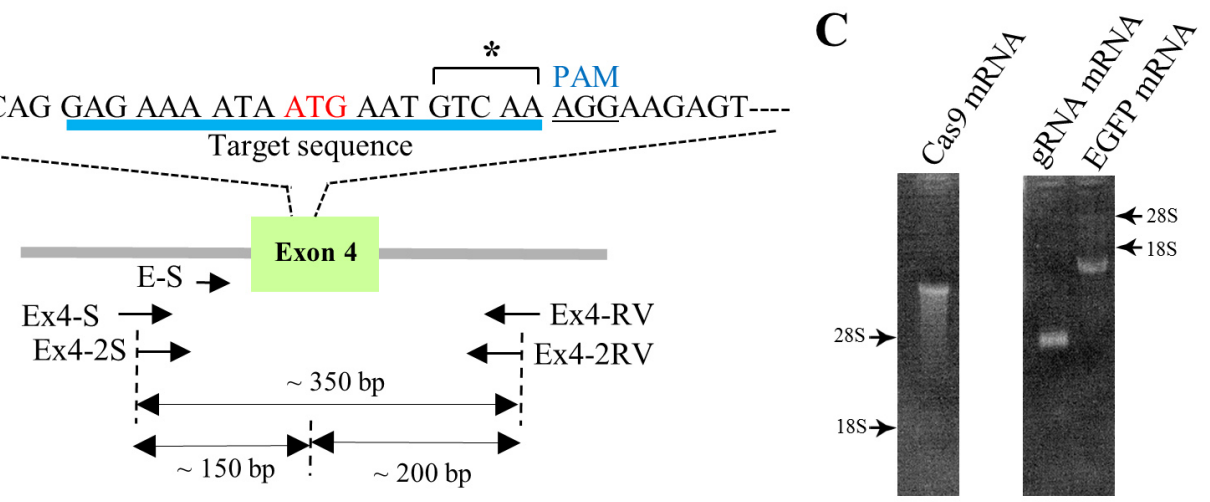

Fig. 1 
A

EGFP

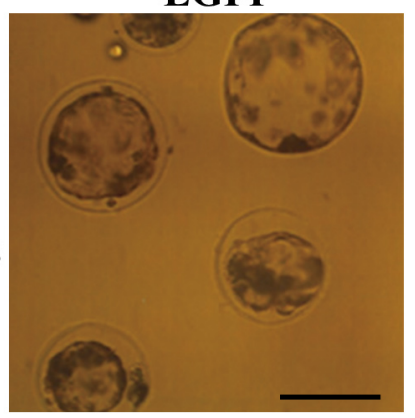

\section{Parthenotes}

\section{Cont}
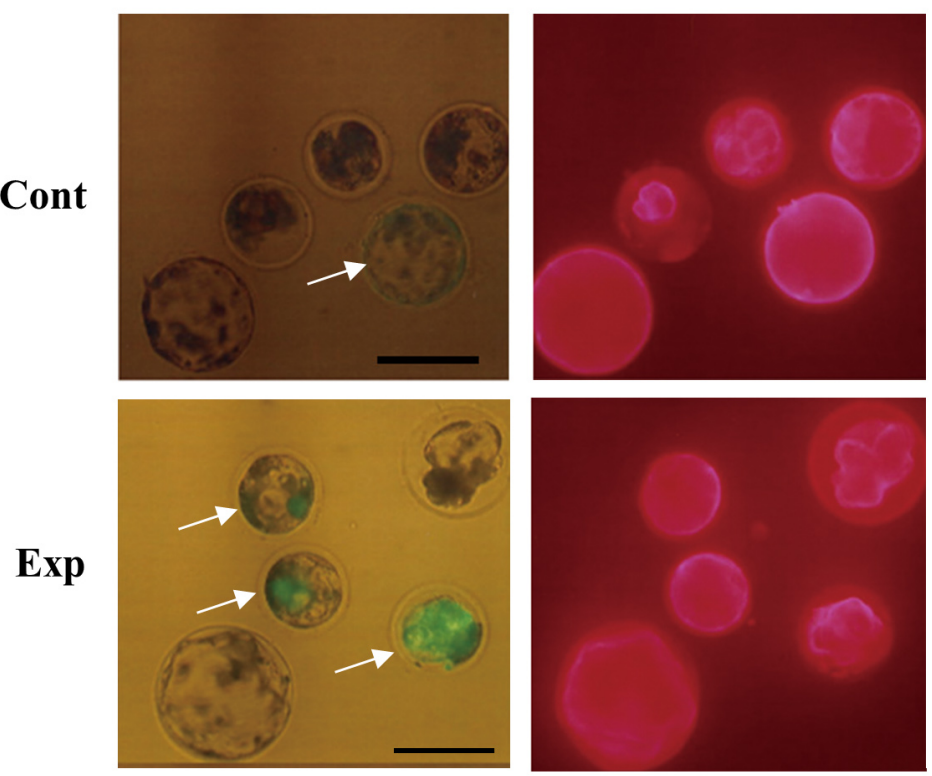

B

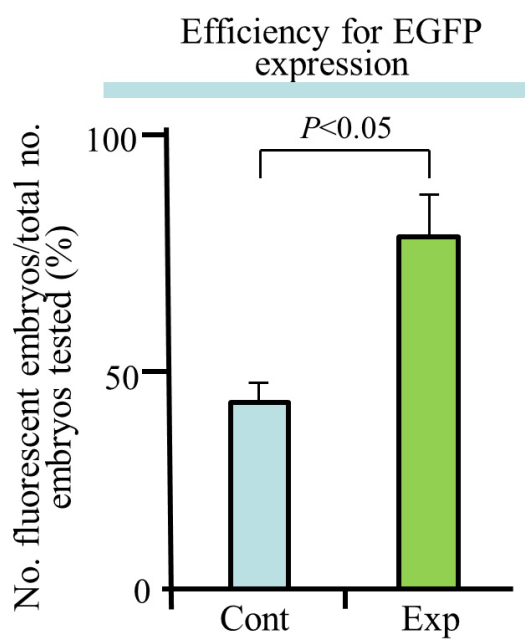

Strength of EGFP fluorescence per blastocyst

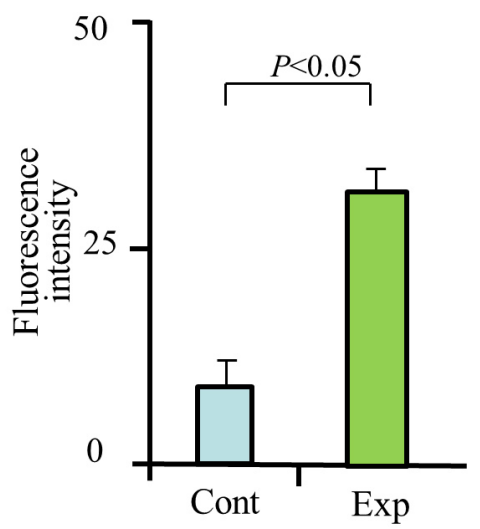

Fig. 2 
A

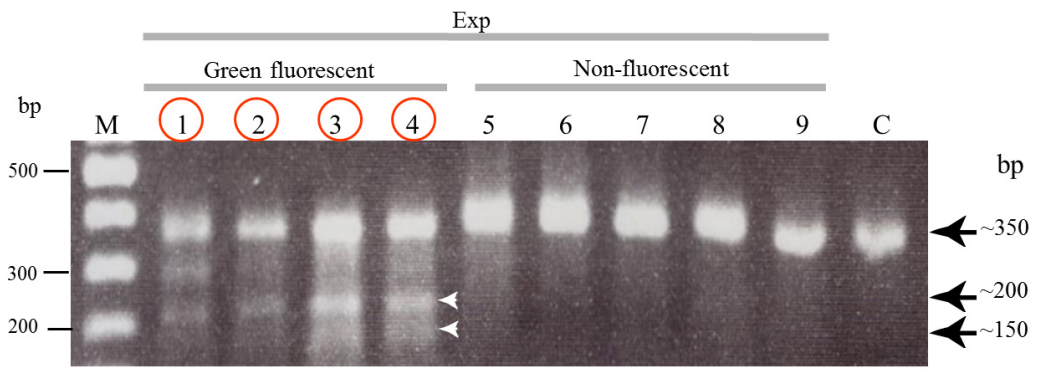

Green fluorescent
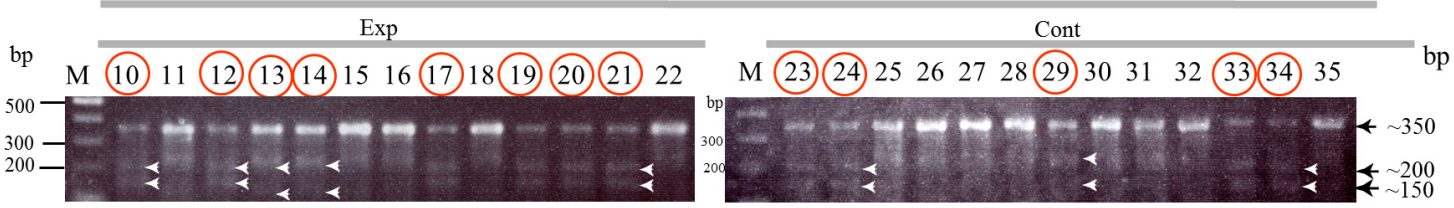

B

Wild-type PEFs

$\underset{40}{\text { CCCA G G AG AAAAT A AT G A T G T CAAAG A A A A A T G G T }}$

\#1 blastocyst

CCCA G G AG AAAATA AT GAT GN CAAAN NANGAN TG GT TC 40

60

70

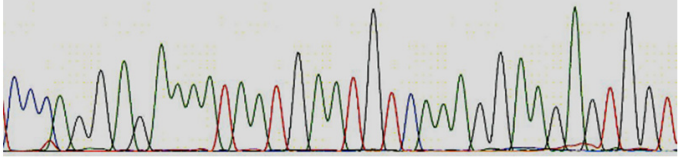

\#2 blastocyst

C C CA G G GAARAA AT AAT GT CAAA GNGAAAATG

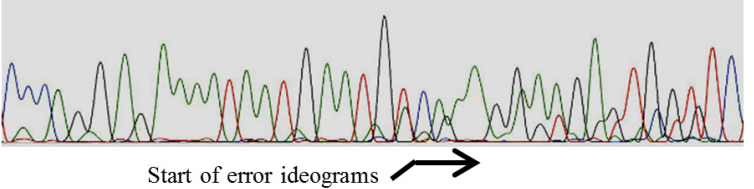

\#3 blastocyst

CCCA G G AGAAAATAAT GAATGTNNNNGNNANNGN

50

60

70
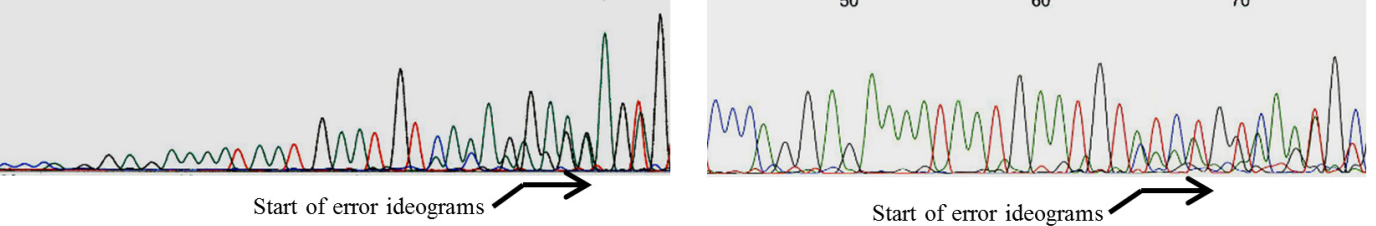

C

\#1 blastocyst-derived clones

No. clones tested: 4; CCCAGGAGAAAATAATG AAT G - - AAA GGA AGA (deletion type)

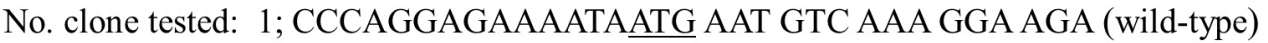

\section{\#2 blastocyst-derived clones}

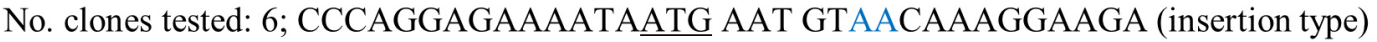

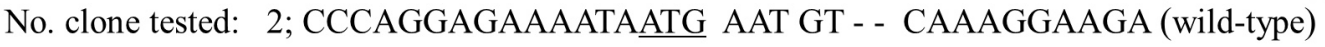

\section{\#3 blastocyst-derived clones}

No. clones tested: 3; CCCAGGAGAAAATAATGAAT GTC TCTGG AAA AGAAGA (insertion type)

No. clones tested: 3; CCCAGGAGAAAATAATGAAT GTA TCTGG AAA AGAAGA (insertion type)

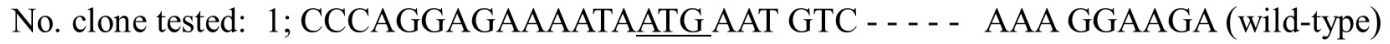

Fig. 3 


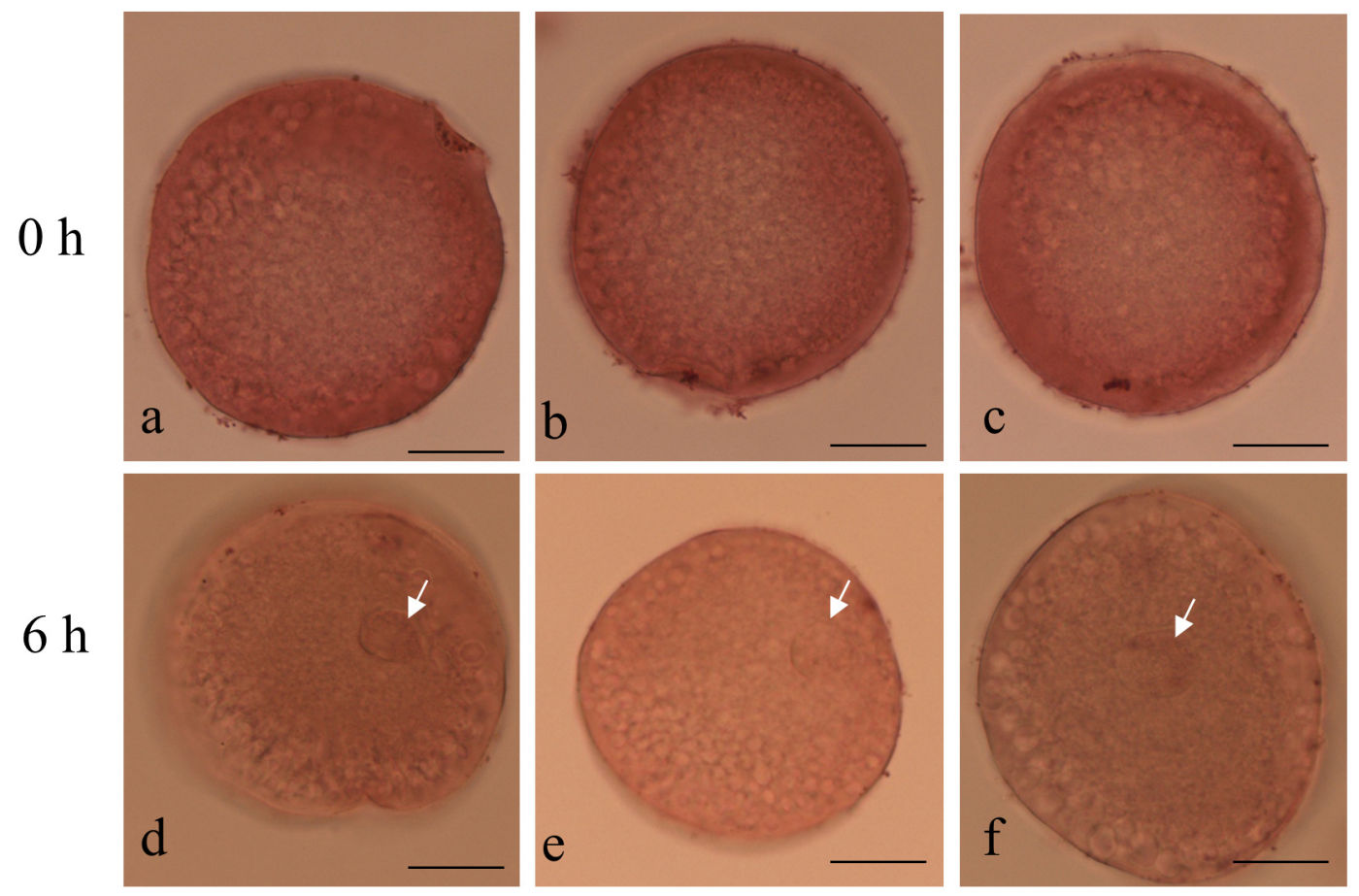

Fig. 4 